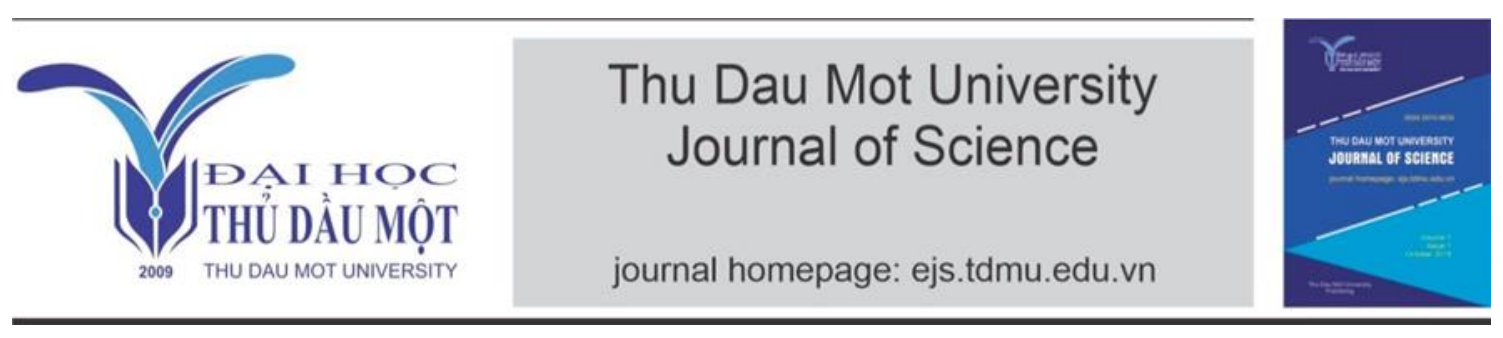

\title{
Analysis of the effects of nutrition and sports on height and weight
}

by Huỳnh Thị Hồng Nhung, Lê Thị Thùy Trang, Nguyễn Thị Xuân, Nguyễn Thị Kim Ngân (Thu Dau Mot University)

Article Info: $\quad$ Received 9 Mar 2021, Accepted 2 Sep 2021, Available online 15 Sep 2021

Corresponding author: nganntk83@tdmu.edu.vn

https://doi.org/10.37550/tdmu.EJS/2021.03.216

\begin{abstract}
This study was conducted on a group of male and female students of age range of 6-11 years at an elementary school. In this paper it is tried to analyze the effects of nutrition and sports on height and weight of male and female students. The result showed that these factors have an impact on students' height and weight, and there were the difference between groups doing sports regularly and rarely, also among groups of different nutrition.
\end{abstract}

Keywords: weight, height, nutrition, sports, nonparametric statistics

\section{Introduction}

This paper illustrates the study of analyzing the influence of nutrition and sports on height and weight of male and female students. Some articles related to this issue such as (Islam et al., 2017), (Juntaping et al., 2017). The survey was conducted at an elementary school among the students of 6-11-year-old. A total of 553 students have signed up of which 276 are male and 277 are female students. The information on gender, age, class, height, weight, nutrition, and sport was collected. The height was calculated in centimeters, and the weight was measured in kilograms. There are three nutritional levels: micronutrient deficiencies, sufficient micronutrients, and excess micronutrients. The same number for levels of doing sport: not practice, sometimes and often. Then, using $\mathrm{R}$ software, we check the distribution of data, and decide to use 
nonparametric statistics. A parallel method with ANOVAwas used is Kruskal-Wallis test, and the post hoc statistic Dunn's test was applied to see the difference among groups.

\section{Computational methods}

In this paper, we use the following tests:

\subsection{Goodness of fit test}

In this type of hypothesis test, we determine whether the data "fit" a particular distribution or not. For example, in this paper, we may suspect our data fit a normal distribution. We use a chi-square test (meaning the distribution for the hypothesis test is chi-square) to determine if there is a fit or not. The null and the alternative hypotheses for this test may be written in sentences or may be stated as equations or inequalities.

The test statistic for a goodness-of-fit test (Nguyễn \& Nguyễn 2019) is: $\sum_{k} \frac{(O-E)^{2}}{E}$ where:

- $O=$ observed values (data)

- $E=$ expected values (from theory)

- $k=$ the number of different data cells or categories

The observed values are the data values and the expected values are the values we would expect to get if the null hypothesis were true. There are $n$ terms of the form $\frac{(O-E)^{2}}{E}$

The number of degrees of freedom is $d f=$ (number of categories -1 ).

\subsection{Kruskal-Wallis One-Way Analysis of Variance}

Kruskal-Wallis One-Way Analysis of Variance (Holmes et al., 2018, Hà, 2010, Kenett et al., 2014) is the nonparametric counterpart to the one-way ANOVA procedure.

$$
\begin{gathered}
\text { H statistic } \\
H=\frac{12}{N(N+1)} \sum_{i=1}^{k} \frac{R_{i}^{2}}{n_{i}}-3(N+1)
\end{gathered}
$$

where

$N$ sum of the sample sizes from all populations

$K$ number of populations

$R_{i}$ sum of ranks in the sample from the $i$ th population

$n_{i}$ size of the sample from the $i$ th population

If $H$ is larger than $\chi^{2}$ from the chi-square distribution with $k-1$ degrees of freedom, the 
hypothesis of equal medians should be rejected.

\subsection{Dunn's Test}

Once the initial ANOVA has found a significant difference in three or more means, Dunn's Test (Hà, 2010) can be used to pinpoint which specific means are significant from the others. Dunn's Multiple Comparison Test is a post hoc non parametric test.

It is one of the least powerful of the multiple comparisons tests and can be a very conservative test - especially for larger numbers of comparisons. For example, if we have 10 comparisons at an alpha level of 0.05 then the formula results in a very percomparison error rate of 0.005 .

The null hypothesis for the test is that there is no difference between groups (groups can be equal or unequal in size).

The alternate hypothesis for the test is that there is a difference between groups.

\section{Data analysis}

The data were recorded using proper computer spread sheet software. There are 553 students and 7 columns of information including identity, class, gender, height (in centimeters), weight (in kilograms), nutrition (with three levels: micronutrient deficiencies, sufficient micronutrients, and excess micronutrients), and sports (not practice, occasional, and regular).

The summary result of the data for the male and females students is given below table-1:

TABLE 1.

\begin{tabular}{|l|c|c|}
\hline & Male & Female \\
\hline Number of participants & 276 & 277 \\
\hline Average Height $(\mathrm{cm})$ & 127.2 & 126.2 \\
\hline Average Weight $(\mathrm{kg})$ & 25.08 & 24.51 \\
\hline
\end{tabular}

For more details, we could use the Summary function in R. For instance, the summary of female students' height and weight are listed below.

$$
\text { Height Weight }
$$

Min. : 100.0 Min. : $: 11.80$

1st Qu.: $: 118.0$ 1st Qu.: 17.00

Median : 126.0 Median $: 23.00$

Mean :126.2 Mean :24.51

3rd Qu.:133.0 3rd Qu.: 30.00

Max. : 152.0 Max. $: 47.00$

Some figures of data. 

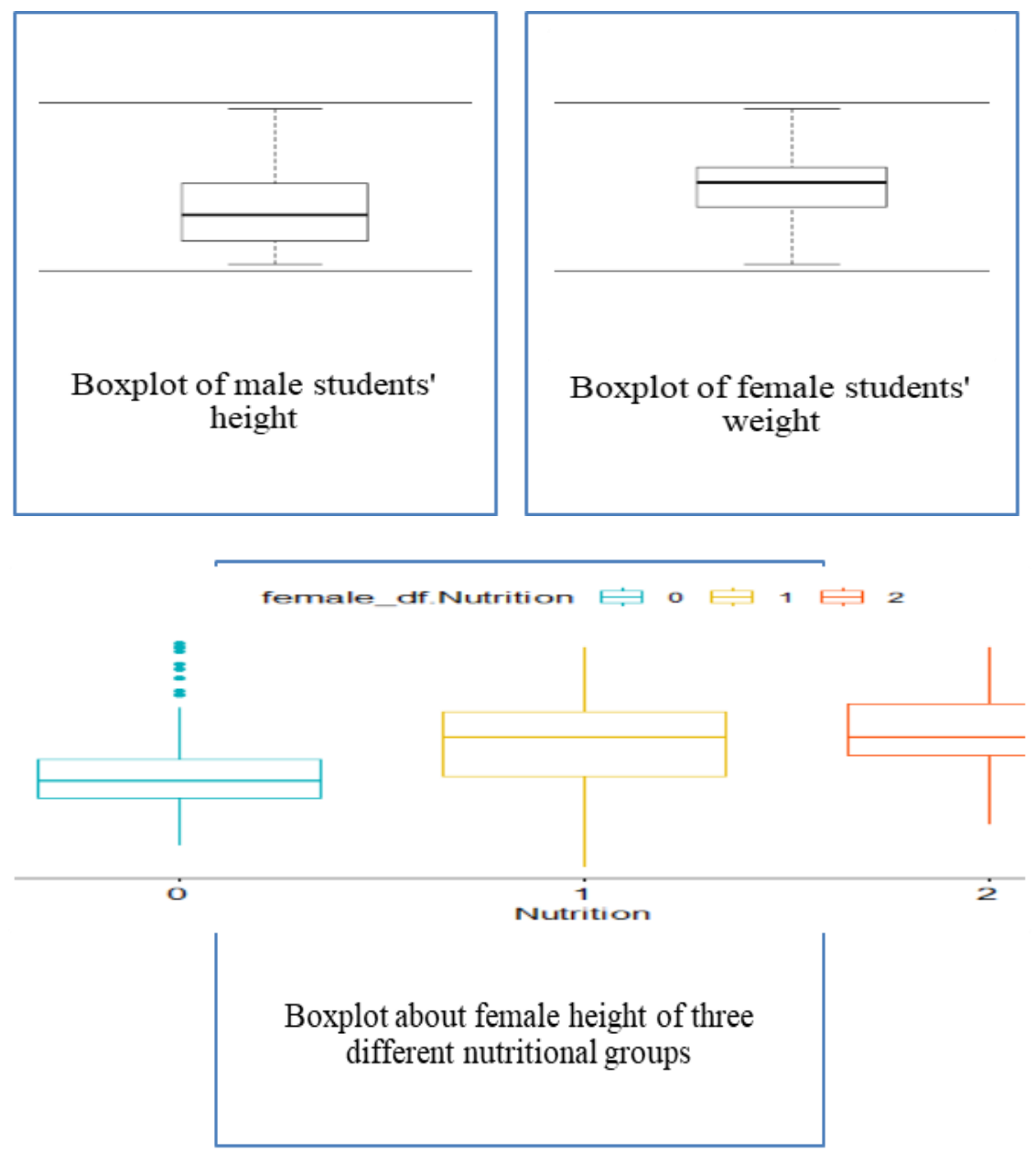

Using Shapiro's test in R to determine the distribution of the data.

Shapiro-Wilk normality test

data:male_df\$Height

$\mathrm{W}=0.97692, \mathrm{p}$-value $=0.0001921$

Since the p-value is less than 0.05 , then the male height data is not normal. Similarly, the female height data, the male weight data, and the female weight data are not normal. Thus, we use the nonparametric test, Kruskal-Wallis test, to see the effect of nutrition and sports on students' height and weight.

Kruskal-Wallis rank sum test

data:male_df.Height by male_df.Nutrition

Kruskal-Wallis chi-squared $=53.775, \mathrm{df}=2, \mathrm{p}$-value $=2.103 \mathrm{e}-12$

Since the p-value is less than 0.05 , the null hypothesis is rejected. That means that nutrition has an influence on male height. Then, use Dunn test to see the difference 
between three height groups for male students.

Dunn (1964) Kruskal-Wallis multiple comparison p-values adjusted with the Benjamini -Hochberg method.

$\begin{array}{ccccc} & \text { Comparison } & Z & \text { P.unadj } & \text { P.adj } \\ \text { 1. } & 0-1 & -5.688234 & 1.283602 \mathrm{e}-08 & 1.925403 \mathrm{e}-08 \\ \text { 2. } & 0-2 & -6.338724 & 2.316762 \mathrm{e}-10 & 6.950285 \mathrm{e}-10 \\ \text { 3. } & 1-2 & -2.281800 & 2.250118 \mathrm{e}-02 & 2.250118 \mathrm{e}-02\end{array}$

The results showed that the average height of the groups with insufficient, sufficient, and excess micronutrient was different.

Similarly, we found that sports affect male students' weight.

Look at female students' data.

Kruskal-Wallis rank sum test

data:female_df.Height by female_df.Nutrition

Kruskal-Wallis chi-squared $=39.332, \mathrm{df}=2, \mathrm{p}$-value $=2.878 \mathrm{e}-09$

Dunn (1964) Kruskal-Wallis multiple comparison

p-values adjusted with the Benjamini-Hochberg method.

$\begin{array}{ccccl} & \text { Comparison } & \text { Z } & \text { P.unadj } & \text { P.adj } \\ 1 & 0-1 & -5.004241 & 5.608255 \mathrm{e}-07 & 8.412383 \mathrm{e}-07 \\ 2 & 0-2 & -5.342762 & 9.154070 \mathrm{e}-08 & 2.746221 \mathrm{e}-07 \\ 3 & 1-2 & -1.149757 & 2.502441 \mathrm{e}-01 & 2.502441 \mathrm{e}-01\end{array}$

Therefore, nutrition affects female height and the average height of the group of deficient micronutrients and the group of sufficient micronutrients is different. The average height of the sufficient micronutrient group and the excess micronutrient group did not differ.

\section{Conclusion}

From the study, it is observed that the average height and weight of male students is higher than of female students. It is also found that nutrition and sports have an impact on height and weight of male and female students. Therefore, parents should pay attention to the child's diet and encourage their children to participate in sports activities.

\section{Acknowledgment}

Thank Ben Suc Primary School in Dau Tieng, Binh Duong for allowing us to have the actual data for this article. 


\section{References}

Hà,V. S. (2010). Giáo trình nguyên lý thống kê kinh tế. Nhà xuất bản thống kê.

Holmes, Illowsky, \& Dean (2018). Introductory bussiness statistics. OpenStax.

Islam, M. R., Shafique, I.B., Rahman, K., \& Haque, A. (2017). A simple study on weight and height of students. European scientific journal, 13(6),1857-7881.

Juntaping, K., Chittawatanarat, K., Prasitwattanaseree, S., Chaijaruwanich, J., \& Traisathit, P. (2017). Relationship between Height-Weight Difference Index and Body-Fat Percentage Estimated by Bioelectrical Impedance Analysis in Thai Adults. Hindawi the Scientific World Journal, https://doi.org/10.1155/2017/7258607

Kenett, R.S.,Zacks, S., \& Amberti, D., (Nguyễn Văn Minh Mẫn dịch) (2014). Thống kê công nghiệp hiện đại với úng dụng viết trên $R$, MINITAB và JMP. Nhà xuất bản Bách khoa Hà Nội.

Nguyễn, T. D., \& Nguyễn, Đ. H. (2019). Xác suất - Thống kê và phân tích số liệu. Nhà xuất bản Đại học quốc gia Thành phố Hồ Chí Minh. 